\title{
Long-Term Effects of Radioiodine Treatment on Salivary Gland Function in Adult Survivors of Pediatric Differentiated Thyroid Carcinoma
}

\author{
Tharsana Selvakumar ${ }^{1}$, Marloes Nies*1, Mariëlle S. Klein Hesselink*1, Adrienne H. Brouwers ${ }^{2}$, Anouk N.A. van der \\ Horst-Schrivers ${ }^{1}$, Esther N. Klein Hesselink ${ }^{1}$, Wim J.E. Tissing ${ }^{3}$, Arjan Vissink ${ }^{4}$, and Thera P. Links ${ }^{1}$ on behalf of the \\ Dutch Pediatric Thyroid Cancer Study Consortium \\ ${ }^{I}$ Department of Endocrinology, University Medical Center Groningen, University of Groningen, Groningen, The Netherlands; \\ ${ }^{2}$ Department of Nuclear Medicine and Molecular Imaging, University Medical Center Groningen, University of Groningen, \\ Groningen, The Netherlands; ${ }^{3}$ Department of Pediatric Oncology, Beatrix Children's Hospital, University Medical Center Groningen, \\ University of Groningen, Groningen, The Netherlands; and ${ }^{4}$ Department of Oral and Maxillofacial Surgery, University Medical \\ Center Groningen, University of Groningen, Groningen, The Netherlands
}

Pediatric differentiated thyroid cancer (DTC) is a rare disease. Initial treatment of DTC consists of a total or near-total thyroidectomy and ${ }^{131}$ I therapy. Previous studies on adults showed that ${ }^{131}$ I treatment may reduce salivary gland function (SGF). Studies regarding SGF in children treated for DTC are sparse. Our aim was to assess the long-term effects of ${ }^{131}$ I treatment on SGF in survivors of pediatric DTC. Methods: In a nationwide cross-sectional study, SGF in patients treated for pediatric DTC between 1970 and 2013 ( $>5$ y after diagnosis, $\geq 18$ y old at the time of evaluation) was studied. SGF was assessed by sialometry, sialochemistry, and a xerostomia inventory. Salivary gland dysfunction (SGD) was defined as an unstimulated whole saliva flow of no more than $0.2 \mathrm{~mL} / \mathrm{min}$ or a stimulated whole saliva flow of no more than $0.7 \mathrm{~mL} / \mathrm{min}$. Results: Sixty-five patients underwent ${ }^{131}$ I treatment (median age at evaluation, $33 \mathrm{y}$, with an interquartile range [IQR] of 25-40 y; $86.2 \%$ female; median follow-up period, $11 \mathrm{y}$, with an IQR of 6-22 y). Median cumulative ${ }^{131}$ I activity was $5.88 \mathrm{GBq}$, with an IQR of 2.92-12.95 GBq, and $47.7 \%$ underwent multiple ${ }^{131} \mathrm{I}$ administrations. SGD was present in $30(47.6 \%)$ patients. Levels of amylase and total protein in saliva were reduced. Moderate to severe xerostomia was present in $22(35.5 \%)$ patients. Stimulated salivary secretion was lower and the severity of xerostomia complaints higher in patients treated with higher cumulative ${ }^{131}$ I activity. Conclusion: In survivors of pediatric DTC, clinically significant SGD was found in $35.5 \%$ and was related to the cumulative ${ }^{131}$ I activity of the treatment.

Key Words: pediatric differentiated thyroid carcinoma; radioiodine treatment; salivary gland dysfunction; xerostomia

J Nucl Med 2019; 60:172-177

DOI: 10.2967/jnumed.118.212449

\footnotetext{
Received Apr. 16, 2018; revision accepted Jun. 18, 2018.

For correspondence or reprints contact: Thera P. Links, Department of Endocrinology, University Medical Center Groningen, University of Groningen, HPC AA31, P.O. Box 30.001, 9700 RB Groningen, the Netherlands. E-mail: t.p.links@umcg.nl

${ }^{*}$ Contributed equally to this work.

Published online Nov. 30, 2018.

COPYRIGHT @ 2019 by the Society of Nuclear Medicine and Molecular Imaging.
}

D ifferentiated thyroid carcinoma (DTC) is the most common type of endocrine malignancy during childhood, and its incidence is increasing (1). Until recently, all pediatric patients were treated with ${ }^{131}$ I as part of the initial treatment of DTC. According to the recently published pediatric management guideline by the American Thyroid Association, ${ }^{131}$ I treatment is indicated only when residual thyroid tissue is present after thyroidectomy or to treat locoregional and distant metastases (2). This guideline shows a trend toward reduced ${ }^{131}$ I activities, based on recent insights that pediatric DTC differs from that in adults and on previous studies showing several adverse effects after ${ }^{131}$ I treatment $(3-8)$. One of these adverse effects is salivary gland dysfunction (SGD), reported in $16 \%-54 \%$ of adult patients (9).

Several theories propose to explain ${ }^{131} \mathrm{I}$ treatment-induced SGD. The ${ }^{131}$ I uptake through the sodium-iodine symporter in salivary gland striated ducts is most likely responsible for the involvement of salivary glands in the adverse effects of ${ }^{131}$ I treatment (10). The accumulation of ${ }^{131} \mathrm{I}$ in salivary glands exposes the cells to the emitted $\beta$-radiation, causing luminal debris, resulting in narrowing and finally obstruction of ducts (5). This obstruction may cause an inflammatory reaction resulting in sialadenitis, characterized by pain and swelling. Another theory proposed that the $\beta$-radiation itself causes an inflammatory reaction, resulting in an increased periductal pressure, leading to narrowing of ducts and subsequently retention of saliva (11).

Markers that may reflect salivary gland function (SGF) are salivary flow rates, alterations in salivary composition, and oral complaints related to reduced salivary secretion (hyposalivation), especially the feeling of dry mouth (xerostomia). Unstimulated whole salivary secretion (UWS) is the flow of saliva in resting, speaking, or sleeping states. Stimulated whole salivary secretion (SWS) is the flow while eating and swallowing. Hyposalivation can result in xerostomia. Alterations in salivary composition can indicate sialadenitis or acinar dysfunction.

Previous studies on adults focused mainly on either qualitative $(8,12,13)$ or quantitative data on SGF (14-16). In pediatric DTC patients, only one study has retrospectively evaluated early and late adverse effects of ${ }^{131}$ I treatment by reviewing medical reports, showing SGD to be present in $1.9 \%$ of the patients, but without defining SGD (8). The severity of damage to the salivary gland in children, compared with adults, either could be greater because of 
their relatively higher exposure to ${ }^{131} \mathrm{I}$ or could be more limited because of their higher regenerative potential. The impact of ${ }^{131} \mathrm{I}$ treatment on the salivary glands in pediatric patients can be more precisely determined when quantitative data on SGF are available.

The aims of this cross-sectional study were to quantitatively assess the long-term effects of ${ }^{131}$ I treatment on the SGF in survivors of pediatric DTC, as well as to analyze the prevalence of SGD in this population. In addition, we evaluated patient and ${ }^{131} \mathrm{I}$ treatment characteristics related to an increased risk of SGD, as well as xerostomia complaints in relation to salivary flow rates.

\section{MATERIALS AND METHODS}

\section{Design and Study Population}

This study is a substudy of a multicenter cross-sectional follow-up study assessing the outcome and long-term effects of pediatric DTC in The Netherlands. In this nationwide follow-up study, all patients $18 \mathrm{y}$ old or less diagnosed with DTC between January 1970 and August 2013 were eligible to participate (17). Exclusion criteria for this substudy were an age less than $18 \mathrm{y}$ at the time of this study, follow-up for less than $5 \mathrm{y}$ after the last ${ }^{131}$ I treatment, DTC as a secondary malignancy, history of externalbeam radiation therapy, and no initial treatment with ${ }^{131} \mathrm{I}$ or missing data on administered ${ }^{131} \mathrm{I}$ activities. All patients were asked to participate in a clinical evaluation involving collection of saliva samples and to complete a xerostomia inventory (XI) (18). The study was approved by the Medical Ethical Committee of the University Medical Center Groningen (ABR NL40572.042.12) and registered at The Netherlands National Trial Registry (NTR3448). Permission was granted by the board of directors of all participating centers, and all subjects provided written informed consent.

\section{Data Collection}

Medical records of patients were used to retrieve data on patient characteristics (sex, age at diagnosis, clinical course, and follow-up time), diagnosis, and treatment. Original pathology reports provided data on tumor characteristics (subtype DTC, TNM classification, lymph node involvement). Reports from the Department of Nuclear Medicine provided data on ${ }^{131} \mathrm{I}$ treatment (number of ${ }^{131} \mathrm{I}$ administrations and cumulative activity). During the ${ }^{131} \mathrm{I}$ treatment, no protective measures regarding SGF were used.

\section{Study Definitions}

Age at diagnosis was defined as the patients' age on the date of histologic confirmation of DTC. At the time of evaluation, the seventh edition of the TNM stage system was valid and used to reclassify the tumor stage (19). All activities that were at least $0.93 \mathrm{GBq}$, irrespective of ablative, therapeutic, or diagnostic application, were included in the calculation of the cumulative ${ }^{131}$ I activity. Follow-up time was calculated from the date of the last ${ }^{131}$ I treatment until the date of collection of the saliva samples. Remission was defined as the absence of clinical, scintigraphic, or radiologic evidence of disease and an undetectable serum level of thyroglobulin under thyroid-stimulating hormone suppressive therapy for at least $1 \mathrm{y}$ after the last ${ }^{131} \mathrm{I}$ administration. SGD was defined as a UWS of no more than $0.20 \mathrm{~mL} / \mathrm{min}$ or an SWS of no more than $0.70 \mathrm{~mL} / \mathrm{min}$ based on previous studies (20-22). Sialadenitis was assessed by studying concentrations of sodium, chloride, or proteins in agreement with previous studies $(5,23)$.

\section{Saliva Collection}

During the clinical visit, UWS and SWS were collected. Patients were not allowed to stimulate the salivary flow $90 \mathrm{~min}$ before saliva was collected, that is, by drinking, chewing, brushing their teeth, using mouthwash, or smoking. Saliva was collected between 9 and $12 \mathrm{AM}$ to minimize the impact of circadian fluctuations during the day.
Salivary flow rates were calculated by dividing the weight of the collected saliva $(\mathrm{g})$ by the collecting time ( $\mathrm{min})$.

UWS. UWS was collected using the drooling method, that is, the patient was allowed to accumulate the saliva in the mouth for $5 \mathrm{~min}$, after which it was passively drained into a preweighed cup.

SWS. SWS was collected after the patient had chewed on a $2.5 \times 2.5 \mathrm{~cm}$ piece of Parafilm (Brand Inc.) for 10 min (masticatory method). At 1-min intervals, the patient expelled the accumulated saliva in a preweighed cup.

\section{Sialochemistry}

Sialochemical analyses were performed on the saliva samples collected during the clinical visit. Sodium and potassium were quantified using atomic emission spectrometry (Thermo Fisher Scientific, Inc.). Chloride, amylase, and total protein were measured using a modular analyzer (Roche). For patients from whom no or minimal saliva could be collected, sialochemical analyses could not be performed.

\section{$\mathbf{X I}$}

Xerostomia-related complaints were evaluated using the XI, a validated questionnaire to assess the severity of xerostomia symptoms (18). The XI consists of 11 items that can be individually scored on a 5-point Likert scale. Patients were asked to choose 1 of 5 possible responses for each item (scoring 1, never; 2 , hardly ever; 3 , occasionally; 4 , fairly often; or 5 , very often) considering the preceding $4 \mathrm{wk}$. Finally, the score of each individual item was tallied into a scale score, ranging from 11 to 55 points. Patients were classified into 3 categories (11-23 points: no to mild complaints, 24-39 points: moderate to severe complaints, $40-55$ points: severe to extreme complaints) based on their total XI score. When one of the items of the XI was accidentally unanswered, patients were excluded from analysis.

\section{Statistical Analysis}

All data were collected and analyzed using IBM SPSS Statistics, version 23, for Microsoft Windows. Categoric data were presented as numbers with percentages, and numeric data were presented as medians with interquartile ranges (IQRs) if the distribution was not normal. Correlation between markers of the SGF (salivary flow rate, XI score, and sialochemical outcomes) and patient and treatment variables (cumulative ${ }^{131}$ I activity, age at evaluation, and follow-up time) were tested using Spearman $\rho$. The Mann-Whitney $U$ test was performed to test the statistical significance of nonnormally distributed variables. All $P$ values were tested 2 -sided, and a $P$ value of 0.05 or less was considered statistically significant. Odds ratios for exhibiting SGD were calculated with $95 \%$ confidence intervals. Consistent statistically significant variables in univariate analysis were entered into the multivariate logistic regression analysis to explore the association of these variables with SGD.

\section{RESULTS}

\section{Patients}

One hundred five survivors of pediatric DTC were included in the nationwide follow-up study (17), of whom 73 were eligible for this substudy. Six patients declined to participate, and the written informed consent of 2 additional participants was received too late to include them in the clinical evaluation. Therefore, 65 patients were included. Two patients declined to participate in the clinical evaluation and were therefore included only in the evaluation of the XI score (Fig. 1). The median age of the participants at the time of diagnosis was $15 \mathrm{y}$, with an IQR of 13-17 y, and 56 (86.2\%) were female (Table 1). Patients took part in the study after a median follow-up time of $11 \mathrm{y}$, with an IQR of 6-22 y, and had a median age of $33 \mathrm{y}$ at the time of clinical evaluation, with an IQR of 25-40 y. Approximately half the patients $(47.7 \%)$ had been treated with 


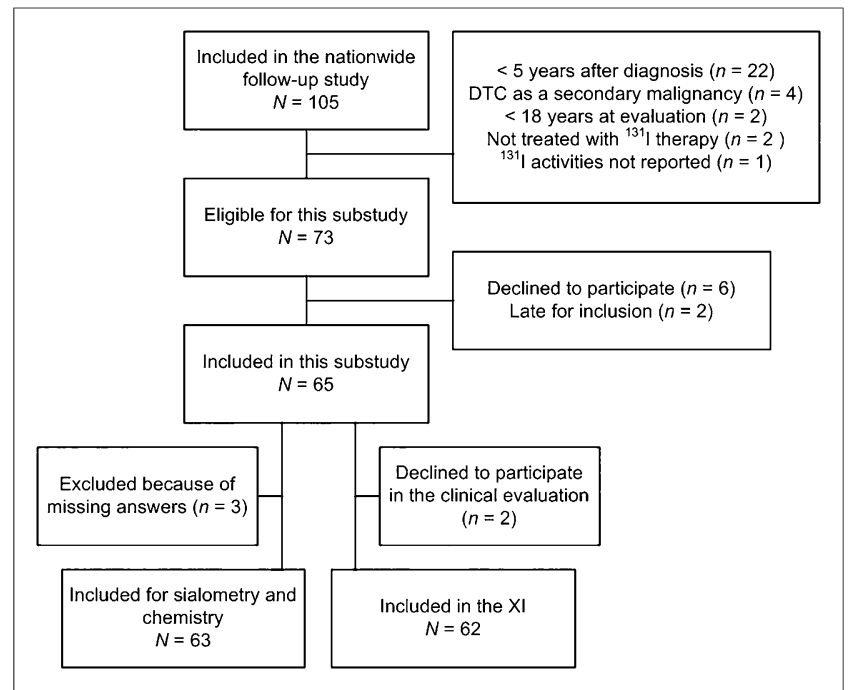

FIGURE 1. Flowchart of inclusion in this study.

multiple ${ }^{131} \mathrm{I}$ administrations. The median cumulative ${ }^{131} \mathrm{I}$ activity administered was $5.88 \mathrm{GBq}$, with an IQR of 2.92-12.95 GBq (Table 2).

\section{Sialometry}

Median UWS was $0.26 \mathrm{~mL} / \mathrm{min}$, with an IQR of $0.18-0.37$ $\mathrm{mL} / \mathrm{min}$, and median SWS was $0.78 \mathrm{~mL} / \mathrm{min}$, with an IQR of 0.64-1.12 $\mathrm{mL} / \mathrm{min}$. UWS and SWS were significantly correlated $(r=0.556, P<0.001)$. Twenty-one patients $(33.3 \%)$ had a UWS of $0.20 \mathrm{~mL} / \mathrm{min}$ or less, and SWS was also $0.70 \mathrm{~mL} / \mathrm{min}$ or less in 21 patients $(33.3 \%)$. According to our definition, 30 patients $(47.6 \%)$ had SGD. Age at time of evaluation was significantly associated with UWS ( $r=-0.259, P=0.041)$ but not with SWS $(r=-0.037, P=$ $0.771)$. Sex did not significantly contribute to differences in salivary flow rates (Supplemental Table 1; supplemental materials are available at http://jnm.snmjournals.org). Cumulative ${ }^{131}$ I activity was significantly associated with SWS $(r=-0.287, P=0.023)$ but not with UWS ( $r=-0.057, P=0.655$ ) (Fig. 2). No significant differences were found in UWS and SWS between patients treated with single and multiple ${ }^{131} \mathrm{I}$ administrations (Supplemental Table 1). Patients treated with cumulative activities of $7.4 \mathrm{GBq}$ or more had significantly lower SWS. Moreover, patients treated with multiple ${ }^{131}$ I administrations had a higher odds of developing SGD (odds ratio, $3.00 ; 95 \%$ confidence interval, $1.07-8.39 ; P=0.036$ ).

\section{Sialochemistry}

Sialochemical outcomes are shown in Table 3. Only potassium and amylase levels in SWS were significantly associated with cumulative ${ }^{131} \mathrm{I}$ activity and number of ${ }^{131} \mathrm{I}$ administrations. In UWS, no sialochemical levels were associated with cumulative ${ }^{131}$ I activity or number of ${ }^{131} \mathrm{I}$ administrations. Patients treated with cumulative activities of 7.4 GBq or more had significantly lower levels of total protein and amylase in SWS (Supplemental Table 1).

\section{$\mathbf{X I}$}

The median total XI score was 22, with an IQR of 16-26. The lowest individual total XI score was 11, and the highest was 40 . The highest median XI scores were for the items "my lips feel dry" and "my mouth feels dry" (Supplemental Table 2). Thirty-nine patients $(62.9 \%)$ had no to mild complaints. In total, 22 patients $(35.5 \%)$ had moderate to severe xerostomia-related complaints, and 1 patient (1.6\%) had severe to extreme complaints (Table 4). The total XI score was significantly associated with cumulative ${ }^{131}$ I activity $(r=0.285, P=0.025)$ and total number of ${ }^{131} \mathrm{I}$ administrations $(r=0.285, P=0.043)$. Patients treated with multiple ${ }^{131} \mathrm{I}$ administrations and cumulative activities of $3.7 \mathrm{GBq}$ or more had significantly higher total XI scores ( $P=0.025$ and $P=0.041$, respectively).

\section{Correlation of Clinical Signs and Salivary Secretion}

The XI score was not statistically significantly related to the UWS or the SWS (Supplemental Fig. 1).

TABLE 1

Baseline Characteristics of the 65 Included Patients at Diagnosis

\begin{tabular}{|c|c|}
\hline Characteristic & Data \\
\hline \multicolumn{2}{|l|}{$\operatorname{Sex}(n)$} \\
\hline Female & $56(86.2)$ \\
\hline Male & $9(13.8)$ \\
\hline \multicolumn{2}{|l|}{ Age at diagnosis } \\
\hline Median (y) & 15 \\
\hline IQR (y) & $13-17$ \\
\hline$<12(n)$ & $7(10.8)$ \\
\hline$\geq 12(n)$ & $58(89.2)$ \\
\hline \multicolumn{2}{|l|}{ Histology $(n)$} \\
\hline PTC & $53(81.5)$ \\
\hline FTC & $12(18.5)$ \\
\hline \multicolumn{2}{|c|}{ Lymph node metastasis $(n)$} \\
\hline Yes & $39(60.0)$ \\
\hline No & $16(24.6)$ \\
\hline Unknown & $10(15.4)$ \\
\hline \multicolumn{2}{|l|}{ TNM classification ( $n)$} \\
\hline \multicolumn{2}{|l|}{ T stage } \\
\hline $\mathrm{T} 1$ & $22(33.8)$ \\
\hline T2 & $18(27.7)$ \\
\hline T3 & $9(13.8)$ \\
\hline T4 & $4(6.2)$ \\
\hline Tx & $12(18.5)$ \\
\hline \multicolumn{2}{|l|}{$\mathrm{N}$ stage } \\
\hline No & $29(44.6)$ \\
\hline N1 & $30(46.2)$ \\
\hline $\mathrm{Nx}$ & $6(9.2)$ \\
\hline \multicolumn{2}{|l|}{ M stage } \\
\hline MO & $52(80.0)$ \\
\hline M1 & $6(9.2)$ \\
\hline $\mathrm{Mx}$ & $7(10.8)$ \\
\hline Stage I & $52(80.0)$ \\
\hline Stage II & $6(9.2)$ \\
\hline Stage unknown & $7(10.8)$ \\
\hline
\end{tabular}

PTC = papillary thyroid cancer; FTC = follicular thyroid cancer. Data are $n$ followed by percentage in parentheses, except for age. 
TABLE 2

Radioiodine Treatment Characteristics

\begin{tabular}{|c|c|c|c|}
\hline Characteristic & No. of patients & Median & IQR \\
\hline No. of ${ }^{131}$ I treatments & & 1 & $1-3$ \\
\hline \multicolumn{4}{|l|}{ Cumulative ${ }^{131} \mid$ activity per ${ }^{131}$ I treatment (GBq) } \\
\hline Only ablation & $34(52.3 \%)$ & 3.7 & $1.85-5.85$ \\
\hline Repeated & $31(47.7 \%)$ & 12.95 & $7.92-18.50$ \\
\hline 2 & $13(20.0 \%)$ & 5.55 & $3.70-5.81$ \\
\hline 3 & $7(10.8 \%)$ & 5.55 & $3.70-5.70$ \\
\hline 4 & $4(6.2 \%)$ & 5.55 & $3.70-5.62$ \\
\hline 5 & $5(7.7 \%)$ & 6.11 & $5.55-7.59$ \\
\hline 6 & $2(3.1 \%)$ & $6.44^{\star}$ & \\
\hline Cumulative ${ }^{131}$ I activity of all patients (GBq) & $65(100 \%)$ & 5.88 & $2.92-12.95$ \\
\hline \multicolumn{4}{|l|}{ Cumulative ${ }^{131}$ I activity (GBq) per TNM stage } \\
\hline Stage I & 52 (80\%) & 5.71 & $2.78-11.75$ \\
\hline Stage II & $6(9.2 \%)$ & 14.43 & $11.24-19.14$ \\
\hline Stage unknown & 7 (10.8\%) & 5.71 & $2.18-8.33$ \\
\hline
\end{tabular}

\section{SGD}

In binary logistic regression analysis, significant predictors in univariate analysis (cumulative ${ }^{131} \mathrm{I}$ activity, number of ${ }^{131} \mathrm{I}$ administrations, and age at time of evaluation) (Supplemental Table 3) were added in the multivariate logistic regression model. Cumulative ${ }^{131} \mathrm{I}$ activity was an independent predictor of SGD adjusted for age at evaluation and number of ${ }^{131} \mathrm{I}$ administrations $(P=0.05)$. Increasing cumulative ${ }^{131}$ I activity was associated with an increased likelihood of salivary gland dysfunction (odds ratio, 1.32; $95 \%$ confidence interval, 1.09-1.61) (Supplemental Table 4).

\section{DISCUSSION}

In this cross-sectional study on the long-term effects of ${ }^{131}$ I treatment on SGF in survivors of pediatric DTC, quantitative and qualitative salivary measurements at long-term follow-up showed that SGF is affected by ${ }^{131} \mathrm{I}$ treatment in almost half the patients. Moreover, a higher cumulative ${ }^{131}$ I activity was found to be associated with lower stimulated salivary flow and more complaints of xerostomia.

Only 1 retrospective study is available on early and late adverse effects of ${ }^{131}$ I treatment in pediatric DTC patients. That study reported that $1.9 \%$ of 105 patients had permanent SGD based on qualitative data from the patient files, but without a clear definition of SGD (8). We objectively assessed SGD by measuring unstimulated and stimulated salivary flow, salivary composition, and xerostomia complaints. Approximately half our patients had stimulated and unstimulated flow rates under a range accepted as normal, and in about a third even below the set cutoff for SGD, suggesting permanent damage or ongoing loss of SGF in patients treated with ${ }^{131}$ I for DTC in childhood, after a median follow-up time of $11 \mathrm{y}$. Decreased salivary flow is one of the manifestations of SGD. Data on salivary flow rates after ${ }^{131} \mathrm{I}$ treatment are not available in pediatric patients and are sparse in adults. In a prospective study on adult patients, significantly decreased unstimulated and stimulated flow rates were found $5 \mathrm{mo}$ after a single ${ }^{131} \mathrm{I}$ treatment as compared with pretreatment (5). Another study on adult patients found salivary flow rates in the reference range, without details regarding the distribution of the follow-up period or the administered ${ }^{131}$ I activities (24).

In contrast to the existing literature on adults (24), we showed a significant association between a higher cumulative ${ }^{131}$ I activity and a lowered stimulated salivary flow. Contradictory results have been found in studies on adults concerning the ${ }^{131} \mathrm{I}$ dose-related effect on SGD $(12,15,25,26)$. Thereby, studies that have shown a ${ }^{131}$ I dose-related effect are hampered by a nonuniform definition of SGD $(12,15,26)$. Our study on survivors of pediatric DTC supports the assumption that the decrease in SGF is ${ }^{131} \mathrm{I}$ dose-related and indicates that SGF is more likely to develop when patients are treated with activities of over $7.4 \mathrm{GBq}$.

The XI scores revealed a ${ }^{131} \mathrm{I}$ dose-related association for the severity of xerostomia. Patients treated with ${ }^{131} \mathrm{I}$ activities of over 3.7 GBq had significantly more xerostomia complaints. In adults, xerostomia is reported as a side effect of ${ }^{131} \mathrm{I}$ treatment, with frequencies ranging from $5 \%$ to $43 \%(27,28)$ and up to $5 \mathrm{y}$ in a small percentage (27). Our study suggests that pediatric patients are even more susceptible to xerostomia when treated with ${ }^{131} \mathrm{I}$, since a third of our study patients had moderate to severe complaints on long-term follow-up.

A significant correlation between salivary flow rate and xerostomia complaints was not found in our study, as agrees with others $(25,29)$. Moreover, although xerostomia could have a significant effect on the quality of life (30), this potential effect might be underestimated, since in most studies questions regarding the presence of oral complaints were nonspecific. Studies on DTC patients that explicitly asked for xerostomia complaints reported a higher prevalence of these complaints than generally assumed by physicians (31).

In most studies, sialadenitis after ${ }^{131}$ I treatment is diagnosed on the basis of clinical signs and has been reported in $2.8 \%-41 \%$ of adult DTC patients $(13,25,26,28)$ and $1.9 \%$ of pediatric DTC patients when measured qualitatively (8). Sialadenitis most often occurs shortly after ${ }^{131}$ I treatment, but an onset after 6 mo and chronic forms are described as well $(32,33)$. To our knowledge, our study is the first that quantitatively evaluated sialadenitis in 


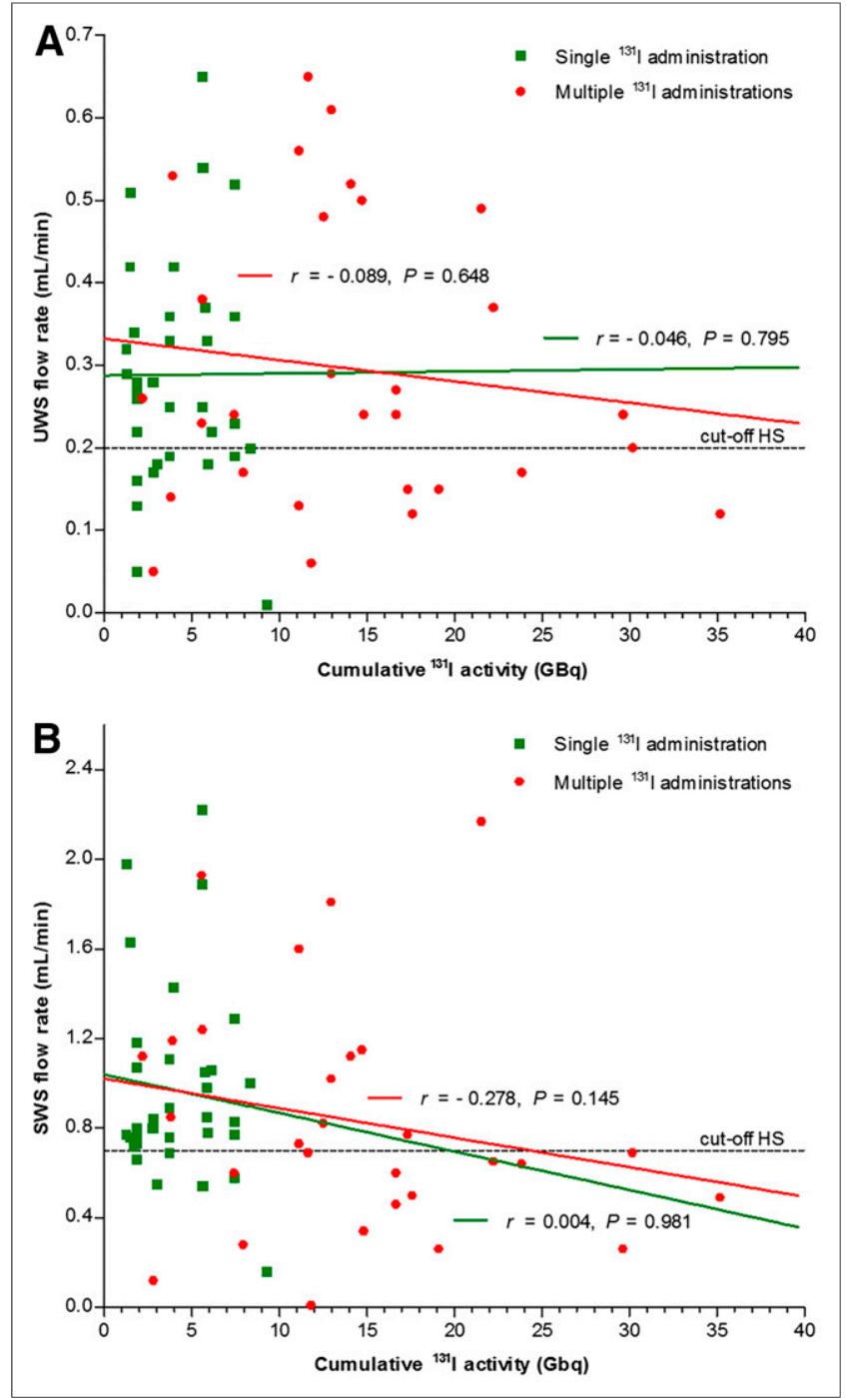

FIGURE 2. Correlation between cumulative ${ }^{131}$ I activity and UWS (A) and SWS (B) flow rates. HS = hyposalivation.

long-term survivors of pediatric DTC by studying salivary composition. We found salivary electrolyte levels in the same range as in healthy individuals, but the levels of total protein and amylase were reduced. These data indicate that in long-term survivors of pediatric DTC, SGF is still affected, although without signs of chronic sialadenitis. Another study on salivary composition in adult patients found no signs of sialadenitis at a mean follow-up of 5 mo after ${ }^{131}$ I treatment (5). A reduced output of amylase was also found in adult patients on short-term follow-up after ${ }^{131} \mathrm{I}$ treatment $(5,34)$ and may suggest acinar dysfunction.

Several mechanisms could be responsible for ${ }^{131}$ I-induced SGD. First, $\beta$-radiation may be directly responsible for an inflammatory reaction, causing an increased periductal pressure, leading to narrowing of ducts and subsequently salivary retention (11). Although this theory may explain the reduced salivary flow rates found in patients soon after ${ }^{131} \mathrm{I}$ treatment, it does not support our finding of persistent reduced salivary flow rates without clinical signs of chronic sialadenitis. On the basis of our results, we presume that irradiation directly affects stem cells in salivary glands, resulting in a reduced regenerative potential (35), responsible for reduced
TABLE 3

Sialochemistry Results

\begin{tabular}{lcc}
\hline Sialochemistry composition & Median & IQR \\
\hline UWS $(n=59)^{\star}$ & & \\
\hline Sodium $(\mathrm{mmol} / \mathrm{L})$ & 5.06 & $3.11-7.78$ \\
\hline Potassium $(\mathrm{mmol} / \mathrm{L})$ & 16.4 & \\
\hline Chloride $(\mathrm{mmol} / \mathrm{L})$ & 15.0 & $12.3-17.0$ \\
\hline Total protein $(\mathrm{g} / \mathrm{L})$ & 0.26 & $0.21-0.38$ \\
\hline Total protein $(\mathrm{mg} / \mathrm{min})$ & 0.07 & $0.05-0.12$ \\
\hline Amylase $\left(10^{3} \mathrm{U} / \mathrm{L}\right)$ & 55.5 & $32.2-95.1$ \\
\hline Amylase $(\mathrm{U} / \mathrm{min})$ & 13.6 & $8.17-24.5$ \\
\hline SWS $(n=62)^{\dagger}$ & & \\
\hline Sodium $(\mathrm{mmol} / \mathrm{L})$ & 8.40 & $5.32-12.1$ \\
\hline Potassium $(\mathrm{mmol} / \mathrm{L})$ & 19.5 & $15.9-23.1$ \\
\hline Chloride $(\mathrm{mmol} / \mathrm{L})$ & 15.0 & $13.0-17.3$ \\
\hline Total protein $(\mathrm{g} / \mathrm{L})$ & 0.26 & $0.19-0.36$ \\
\hline Total protein $(\mathrm{mg} / \mathrm{min})$ & 0.22 & $0.15-0.30$ \\
\hline Amylase $\left(10^{3} \mathrm{U} / \mathrm{L}\right)$ & 68.5 & $45.7-103$ \\
\hline Amylase $(\mathrm{U} / \mathrm{min})$ & 53. & $31.4-94.4$ \\
\hline
\end{tabular}

${ }^{*}$ Chloride and total protein levels were analyzed in 60 patient samples.

†Sodium levels were analyzed in 61 patient samples.

salivary flow rates and associated xerostomia complaints. The patients studied had been treated with a fixed dose of ${ }^{131} \mathrm{I}$ in childhood, similar to the dose given to adults, thereby receiving relatively higher activities of ${ }^{131} \mathrm{I}$ per kilogram of body weight than is given to adults and exposed to radiation in a crucial period of their growth and development. Our long-term results showing reduced salivary flow rates suggest that irradiation may have more severe effects on children than adults and causes permanent damage.

This study has several limitations. First, it was conducted on a relatively small number of patients because of the rarity of pediatric DTC. Moreover, data, especially on diagnostic application activities of ${ }^{131} \mathrm{I}$, could not be completely retrieved from nuclear reports because of the retrospective character of the study. Since sialochemical analysis could not be performed on some saliva samples of patients with minimal to no saliva secretion, our results possibly underestimate the damage of salivary glands in our patients. Furthermore, because of lack of quantitative salivary data in survivors of pediatric DTC, we could compare our data only with data from

TABLE 4

Classification XI Scores

\begin{tabular}{ccc}
\hline Classification & Total XI score & No. of patients ${ }^{*}$ \\
\hline No to mild complaints & $11-23$ & $39(62.9 \%)$ \\
\hline $\begin{array}{c}\text { Moderate to severe } \\
\text { complaints }\end{array}$ & $24-39$ & $22(35.5 \%)$ \\
\hline $\begin{array}{c}\text { Severe to extreme } \\
\text { complaints }\end{array}$ & $40-55$ & $1(1.6 \%)$ \\
\hline
\end{tabular}

*62 total. 
studies on adult patients. However, since we obtained both quantitative and qualitative data indicating a toxic effect of ${ }^{131}$ I treatment, we believe that our study shows important and clinically relevant results, despite these limitations.

\section{CONCLUSION}

Our study showed that ${ }^{131} \mathrm{I}$ treatment in pediatric DTC patients has damaging long-term effects on multiple markers of SGF, both qualitatively and quantitatively, and that these effects are associated with the administered cumulative ${ }^{131}$ I activity. Our data suggest the importance of greater emphasis on prevention and early recognition of SGD. Moreover, these data support the importance of restriction of radioactivity required for therapeutic purposes in children as has already been emphasized in the American Thyroid Association guidelines for pediatric DTC.

\section{DISCLOSURE}

No potential conflict of interest relevant to this article was reported.

\section{ACKNOWLEDGMENTS}

The Dutch Pediatric Thyroid Cancer study consortium comprises Gianni Bocca, University Medical Center Groningen; Johannes G.M. Burgerhof, University Medical Center Groningen; Eveline W.C.M. van Dam, VU University Medical Center; Bas Havekes, University Medical Center Maastricht; Marry M. van den HeuvelEibrink, Princess Maxima Center for Pediatric Oncology; Eleonora P.M. Corssmit, University Medical Center Leiden; Leontine C.M. Kremer, AMC and Princess Maxima Center for Pediatric Oncology; Romana T. Netea-Maier, University Medical Center Radboud; Heleen J.H. van der Pal, University Medical Center Amsterdam; Robin P. Peeters, University Medical Center Erasmus; Johannes W.A. Smit, University Medical Center Radboud; John T.M. Plukker, University Medical Center Groningen; Cecile M. Ronckers, University Medical Center Amsterdam and Princess Maxima Center for Pediatric Oncology; and Hanneke M. van Santen, Wilhelmina Children's Hospital, University Medical Center Utrecht.

\section{REFERENCES}

1. Hogan AR, Zhuge Y, Perez EA, Koniaris LG, Lew JI, Sola JE. Pediatric thyroid carcinoma: incidence and outcomes in 1753 patients. J Surg Res. 2009;156:167-172.

2. Francis GL, Waguespack SG, Bauer AJ, et al. Management guidelines for children with thyroid nodules and differentiated thyroid cancer. Thyroid. 2015;25:716-759.

3. Brown AP, Chen J, Hitchcock YJ, Szabo A, Shrieve DC, Tward JD. The risk of second primary malignancies up to three decades after the treatment of differentiated thyroid cancer. J Clin Endocrinol Metab. 2008;93:504-515.

4. Iyer NG, Morris LGT, Tuttle RM, Shaha AR, Ganly I. Rising incidence of second cancers in patients with low-risk (T1N0) thyroid cancer who receive radioactive iodine therapy. Cancer. 2011;117:4439-4446.

5. Klein Hesselink EN, Brouwers AH, de Jong JR, et al. Effects of radioiodine treatment on salivary gland function in patients with differentiated thyroid carcinoma: a prospective study. J Nucl Med. 2016;57:1685-1691.

6. Hyer S, Vini L, O'Connell M, Pratt B, Harmer C. Testicular dose and fertility in men following $\mathrm{I}^{131}$ therapy for thyroid cancer. Clin Endocrinol $(O x f)$. 2002;56:755-758.

7. Vini L, Hyer S, Al-Saadi A, Pratt B, Harmer C. Prognosis for fertility and ovarian function after treatment with radioiodine for thyroid cancer. Postgrad Med J. 2002;78:92-93.

8. Albano D, Bertagna F, Panarotto MB, Giubbini R. Early and late adverse effects of radioiodine for pediatric differentiated thyroid cancer. Pediatr Blood Cancer. 2017;64:e26595.
9. Clement SC, Peeters RP, Ronckers CM, et al. Intermediate and long-term adverse effects of radioiodine therapy for differentiated thyroid carcinoma: a systematic review. Cancer Treat Rev. 2015;41:925-934.

10. La Perle KM, Kim DC, Hall NC, et al. Modulation of sodium/iodide symporter expression in the salivary gland. Thyroid. 2013;23:1029-1036.

11. Mandel SJ, Mandel L. Radioactive iodine and the salivary glands. Thyroid. 2003;13:265-271.

12. Hyer S, Kong A, Pratt B, Harmer C. Salivary gland toxicity after radioiodine therapy for thyroid cancer. Clin Oncol (R Coll Radiol). 2007;19:83-86.

13. Walter MA, Turtschi CP, Schindler C, Minnig P, Müller-Brand J, Müller B. The dental safety profile of high-dose radioiodine therapy for thyroid cancer: longterm results of a longitudinal cohort study. J Nucl Med. 2007;48:1620-1625.

14. Caglar M, Tuncel M, Alpar R. Scintigraphic evaluation of salivary gland dysfunction in patients with thyroid cancer after radioiodine treatment. Clin $\mathrm{Nucl}$ Med. 2002;27:767-771.

15. Jeong SY, Kim HW, Lee S, Ahn B, Lee J. Salivary gland function 5 years after radioactive iodine ablation in patients with differentiated thyroid cancer: direct comparison of pre- and postablation scintigraphies and their relation to xerostomia symptoms. Thyroid. 2013;23:609-616.

16. An YS, Yoon J, Lee SJ, Song H, Yoon S, Jo K. Symptomatic late-onset sialadenitis after radioiodine therapy in thyroid cancer. Ann Nucl Med. 2013;27:386-391.

17. Klein Hesselink MS, Nies M, Bocca G, et al. Pediatric differentiated thyroid carcinoma in the Netherlands: a nationwide follow-up study. J Clin Endocrinol Metab. 2016;101:2031-2039.

18. Thomson WM, Chalmers JM, Spencer AJ, Williams SM. The xerostomia inventory: a multi-item approach to measuring dry mouth. Community Dent Health. 1999;16:12-17.

19. Edge SB, Compton CC. The American Joint Committee on Cancer: the 7th ed. of the AJCC cancer staging manual and the future of TNM. Ann Surg Oncol. 2010;17: 1471-1474.

20. Navazesh M, Christensen C, Brightman V. Clinical criteria for the diagnosis of salivary gland hypofunction. J Dent Res. 1992;71:1363-1369.

21. Sreebny LM, Valdini A. Xerostomia. Part I: relationship to other oral symptoms and salivary gland hypofunction. Oral Surg Oral Med Oral Pathol. 1988;66:451-458.

22. Sreebny LM, Vissink A. Dry Mouth: The Malevolent Symptom-A Clinical Guide. 1st ed. Ames, IA: Wiley-Blackwell; 2010.

23. Maier $\mathrm{H}$, Bihl $\mathrm{H}$. Effect of radioactive iodine therapy on parotid gland function. Acta Otolaryngol. 1987;103:318-324.

24. Laupa MS, Toth BB, Keene HJ, Sellin RV. Effect of radioactive iodine therapy on salivary flow rates and oral Streptococcus mutans prevalence in patients with thyroid cancer. Oral Surg Oral Med Oral Pathol. 1993;75:312-317.

25. Almeida JP, Sanabria AE, Lima ENP, Kowalski LP. Late side effects of radioactive iodine on salivary gland function in patients with thyroid cancer. Head Neck. 2011;33:686-690.

26. Lee SM, Lee JW, Kim SY, Han SW, Bae WK. Prediction of risk for symptomatic sialadenitis by post-therapeutic dual ${ }^{131} \mathrm{I}$ scintigraphy in patients with differentiated thyroid cancer. Ann Nucl Med. 2013;27:700-709.

27. Alexander C, Bader JB, Schaefer A, Finke C, Kirsch CM. Intermediate and longterm side effects of high-dose radioiodine therapy for thyroid carcinoma. $\mathrm{J} \mathrm{Nucl}$ Med. 1998;39:1551-1554.

28. Silberstein EB. Reducing the incidence of ${ }^{131} \mathrm{I}$-induced sialadenitis: the role of pilocarpine. J Nucl Med. 2008;49:546-549.

29. Bergdahl M, Bergdahl J. Low unstimulated salivary flow and subjective oral dryness: association with medication, anxiety, depression, and stress. J Dent Res. 2000;79: 1652-1658.

30. Memtsa PT, Tolia M, Tzitzikas I, et al. Assessment of xerostomia and its impact on quality of life in head and neck cancer patients undergoing radiation therapy. Mol Clin Oncol. 2017;6:789-793.

31. Aschebrook-Kilfoy B, James B, Nagar S, et al. Risk factors for decreased quality of life in thyroid cancer survivors: initial findings from the North American Thyroid Cancer Survivorship Study. Thyroid. 2015;25:1313-1321.

32. Allweiss P, Braunstein GD, Katz A, Waxman A. Sialadenitis following I-131 therapy for thyroid carcinoma: concise communication. J Nucl Med. 1984;25:755-758.

33. Grewal RK, Larson SM, Pentlow CE, et al. Salivary gland side effects commonly develop several weeks after initial radioactive iodine ablation. J Nucl Med. 2009;50:1605-1610.

34. Schneyer LH. Effect of administration of radioactive iodine on human salivary gland function. J Dent Res. 1953;32:63-69.

35. van Luijk P, Pringle S, Deasy JO, et al. Sparing the region of the salivary gland containing stem cells preserves saliva production after radiotherapy for head and neck cancer. Sci Transl Med. 2015;7:305ra147. 